\title{
Assessment of the response to gluten-free diet in an Iraqi population with coeliac disease. A histological and serological follow-up study
}

\author{
Muhamed Osman ${ }^{1}$, Balsam Taha², Ghada Al Duboni ${ }^{3}$
}

\author{
1Department of Pathology, Faculty of Medicine and Defence Health, University \\ Pertahanan Malaysia (UPNM), Kuala Lumpur, Malaysia \\ 2Specialized Surgeries Hospital, Medical City, Baghdad, Iraq \\ ${ }^{3}$ Clinical Immunologist, Department of Basic Sciences, College of Dentistry, \\ University of Baghdad, Baghdad, Iraq
}

Submitted: 27 January 2012

Accepted: 11 March 2012

Arch Med Sci 2014; 10, 2: 294-299

DOI: $10.5114 /$ aoms.2012.31297

Copyright @ 2014 Termedia \& Banach

\section{Abstract}

Introduction: Coeliac disease (CD) is a common diagnosis among children and adults in Iraq; however, removal of gluten from the diet is essential for patients with CD. The aim of this study, the first such study in Iraq, was to assess the serological and histological recovery profiles of coeliac patients, in both children and adults groups after commencing a gluten-free diet (GFD) for at least 1 year \pm 1 month.

Material and methods: The study group comprised 78 proved coeliac patients (46 children and 32 adults, median age: 15 years, range: 1-66 years) who all agreed to undergo endoscopy in addition to serological assessment before and after treatment. The duodenal biopsies were interpreted histologically according to modified Marsh criteria and the sera were tested for anti-gliadin antibody (AGA), endomysium antibody (EMA) and anti-tissue transglutaminase antibody (tTG).

Results: Complete histological remission was seen in 29 (63.1\%) of 46 treated children CD patients, while only 5 (10.9\%) showed Marsh IIla changes compared with 11 (24\%) before GFD. Similarly none of the 32 adults after GFD showed Marsh IIIb and Marsh IIIc compared with $46.9 \%$ and $28.1 \%$ before treatment respectively $(p=001)$. Meanwhile, there was strongly significant reduction in AGA, EMA, and tTG antibodies levels $(p=0.00001)$ following GFD.

Conclusions: Repeating the duodenal biopsy 1 year \pm 1 month after diagnosis and starting a GFD supports the routine measurement of using histological findings as a gold standard test to confirm recovery of Iraqi CD patients along with using known coeliac serology antibodies.

Key words: coeliac disease, gluten-free diet, anti-gliadin antibodies, endomysial antibody, anti-tissue-transglutaminase antibodies.

\section{Introduction}

Coeliac disease (CD) is a permanent state of intolerance to gluten, i.e., alcohol-insoluble proteins of wheat, rye, and barley [1]. The immunological response to gluten in gluten-sensitive people causes appearance of coeliac serological antibodies beside histological abnormalities of the small intestinal mucosa, comprising influx of lymphocytes into the epithelium, crypt hyperplasia, and, ultimately, villous atrophy [2]. This results in various symptoms and signs of malabsorption [1, 2]; however, removal of gluten from the diet is essential for patients with CD [2].
Corresponding author: Assoc. Prof. Dr. Muhamed T. Osman Department of Pathology Faculty of Medicine and Defence Health University Pertahanan Malaysia (UPNM) Kem Sungai Besi, 57000 Kuala Lumpur, Malaysia Phone: +60390513400 E-mail: mtosman2004@gmail.com 
Serological testing has a well-established place in the diagnosis and screening of $C D$ and in this setting anti-gliadin antibodies (AGA), antiendomysial antibodies (EMA) and anti-tissue transglutaminase antibodies (tTG) are useful and have been compared and reviewed in many studies [1-5].

After commencing a gluten-free diet (GFD), symptoms improve within weeks and coeliac antibodies may normalize within 6-12 months [3]. Guidelines have traditionally recommended that follow-up endoscopy and biopsies should be performed after commencing a GFD to document the histological improvement and to confirm the clinical remission and dietary compliance [5-7]. Follow-up endoscopy after 4-6 months on a GFD is considered as the gold standard in evaluating dietary compliance $[7,8]$; meanwhile, frequently repeated biopsies are neither practical nor cost-effective so that the followup data on serologic markers negativity and small intestinal recovery in CD are scarce and contradictory. Shmerling and Franckx [9] reported complete normalization of the small intestinal mucosa with negative serological markers in all of 91 children with $C D$ who were on a gluten-free diet. Congdon et al. [10] found persisting villous atrophy in 2 of 10 children with CD. Grefte et al. reported slow and incomplete histological and functional recovery in 22 adults with CD after 24 to 48 months of a gluten-free diet.

Coeliac disease is a common diagnosis among children and adults in Iraq [12-15]; however, followup study of CD has not yet been carried out in Iraq. The aim of the present study was to assess the serological and histological recovery profiles of Iraqi coeliac patients after commencing a GFD, who were seen in medical city hospitals during a 5-year period.

\section{Material and methods}

This study included 78 consecutive untreated coeliac patients ( 46 children ( 26 female, 20 male) and 32 adults (14 female, 18 male), median age: 15 years, range: 1-66 years) referred to Medical City hospitals in Baghdad, during a period of five years.

Duodenal biopsy was performed in all patients on the bases of clinical history and serological assessment, including AGA, EMA, tTG antibodies testing.

Biopsies were interpreted by two pathologists who were not informed about the clinical status of the patients and interpreted small intestinal histological features, according to the Marsh classification and the modified Marsh criteria [16, 17]: Marsh I consists of raised intraepithelial lymphocytes (IELs) with > 40 lymphocytes per 100 enterocytes, Marsh II consists of raised intraepithelial lymphocytes and crypt hyperplasia, Marsh Illa partial villous atrophy, Marsh IIIb subtotal villous atrophy, and Marsh IIIC total villous atrophy.
A follow-up biopsy and serological monitoring were repeated at 1 year \pm 1 month after gluten withdrawal. Serum IgA EMA was detected qualitatively by the indirect immunofluorescent (IIF) method using commercial slides of monkey esophagus (from Medic Company, Italy), with reticular staining of the muscularis mucosa at serum dilution of $1: 3$ reported as positive. However, AGA and tTG were performed by enzyme-linked immunosorbent assay (ELISA) in duplicate and according to the manufacturers' instructions.

All patients gave informed written consent and the study was approved by the Ethics Committee of the College of Medicine, University of Baghdad.

\section{Statistical analysis}

Analysis comprised summary statistics for gender and age, and comparative analysis between the findings before and after GFD. Data were analysed using SPSS v10 for Windows and paired $t$-tests were used to compare the change in histopathology findings (Marsh grade) after the follow-up period. Data values were adjusted for age and initial values. Analyses where the $p$-value was $<0.05$ were considered to be statistically significant.

\section{Results}

Since children with CD differ from adults in certain aspects, the associations presented in this study were grouped into two categories; first, children ( $<18$ years) (female to male ratio: $1.29: 1)$; second, adults ( $\geq 18$ years) (female to male ratio: $0.82: 1$ ).

At study enrollment, all subjects had to have villous atrophy (Marsh stage III), to be eligible to participate in the follow-up study. Table I shows a comparison between histopathological results in coeliac patients before and after GFD according to age group. Complete histological remission was seen in 29 (63.1\%) of 46 treated children CD patients within 1 year \pm 1 month, while only $5(10.9 \%)$ treated children with CD showed Marsh IIla changes compared with 11 (24\%) before GFD; these patients are known as histological non-responders. Only 2/46 (4.3\%) treated children coeliacs showed Marsh IIIb compared with 22 (47.8\%) before GFD, while none of the treated children coeliacs showed Marsh IIIC (these are also known as histological responders) compared with $28.2 \%$ before treatment. Similar results were obtained in adult CD patients, in whom only 1 patient (3.1\%) showed Marsh Illa compared with $25 \%$ of patients before GFD, while none of the adults after GFD showed Marsh IIIb and Marsh IIIC compared with $46.9 \%$ and $28.1 \%$ before treatment respectively $(p=001)$.

At baseline, 41 (89.1\%) of 46 children CD patients were positive to AGA while 5 patients (10.9\%) were negative. At the 1 year \pm 1 month follow-up, the 
AGA level had normalized in 43 (93.5\%) of the 46 subjects. Overall, there was a significant reduction in AGA levels $(p=0.0001)$ following a GFD. Meanwhile, $22(68.7 \%)$ of 32 adult CD patients were positive to AGA at baseline. At the 1 year \pm 1 month follow-up, the AGA level had normalized in all adult $C D$ patients; this was a strongly significant reduction in AGA ( $p=0.00001)$ (Table II).

As shown in Table III, at baseline, 43 (93.5\%) of 46 children CD patients were positive to IgA EMA, while 3 patients (6.5\%) were negative. At the 1 year \pm 1 month follow-up, the EMA had normalized in 44 $(95.7 \%)$ of the 46 patients. There was a significant reduction in EMA ( $p=0.0001)$. However, all $32(100 \%)$ adult $C D$ patients were positive for EMA at baseline, while none of these 32 treated adult $C D$ patients showed positive EMA at the 1 year \pm 1 month followup; this was a strongly significant reduction in EMA $(p=0.00001)$.

Similarly to the results for EMA, at baseline 43 (93.5\%) of 46 children CD patients were positive to
IgA tTG antibodies while 3 patients (6.5\%) were negative, but at the 1 year \pm 1 month follow-up, the tTG antibody level had normalized in 42 (91.3\%) of the 46 children. Overall, there was a significant reduction in tTG levels $(p=0.0001)$ following a GFD. However, all 32 adult CD patients were positive for tTG at baseline, but at the 1 year \pm 1 month followup, the tTG level had normalized in all adult CD patients; there was also a strongly significant reduction in tTG antibody levels ( $p=0.00001)$ (Table IV).

\section{Discussion}

A trial was done to assess the response to commencing a GFD in our coeliac patients as the first study in an Iraqi population to prospectively examine histological and serological findings 1 year \pm 1 month after the first diagnosis.

Compliance with a GFD is likely protective against the development of non-Hodgkin's lymphoma in CD and dermatitis herpetiformis. There is compelling evidence that treatment of symptomatic CD with

Table I. Comparison between histopathological results in coeliac patients before and after GFD according to age group

\begin{tabular}{|c|c|c|c|c|c|c|}
\hline & \multirow[t]{2}{*}{ Histopathology } & \multicolumn{2}{|c|}{ Before GFD } & \multicolumn{2}{|c|}{ After GFD } & \multirow[t]{2}{*}{ Value of $p$} \\
\hline & & $N$ & $\%$ & $N$ & $\%$ & \\
\hline \multirow[t]{7}{*}{ Coeliac children } & Marsh I & 0 & 0 & 7 & 15.2 & \\
\hline & Marsh II & 0 & 0 & 3 & 6.5 & \\
\hline & Marsh IIla & 11 & 24 & 5 & 10.9 & \\
\hline & Marsh IIIb & 22 & 47.8 & 2 & 4.3 & \\
\hline & Marsh IIIC & 13 & 28.2 & 0 & 0 & \\
\hline & Normal histology & 0 & 0 & 29 & 63.1 & \\
\hline & Total & 46 & 100 & 46 & 100 & 0.001 \\
\hline \multirow[t]{7}{*}{ Coeliac adults } & Marsh I & 0 & 0 & 3 & 9.4 & \\
\hline & Marsh II & 0 & 0 & 2 & 6.2 & \\
\hline & Marsh IIla & 8 & 25 & 1 & 3.1 & \\
\hline & Marsh IIIb & 15 & 46.9 & 0 & 0 & \\
\hline & Marsh IIIC & 9 & 28.1 & 0 & 0 & \\
\hline & Normal histology & 0 & 0 & 26 & 81.3 & \\
\hline & Total & 32 & 100 & 32 & 100 & 0.001 \\
\hline
\end{tabular}

Table II. Comparison between AGA tests in coeliac patients before and after GFD according to age group

\begin{tabular}{|c|c|c|c|c|c|c|}
\hline & \multirow[t]{2}{*}{ AGA } & \multicolumn{2}{|c|}{ Before GFD } & \multicolumn{2}{|c|}{ After GFD } & \multirow[t]{2}{*}{ Value of $p$} \\
\hline & & $N$ & $\%$ & $N$ & $\%$ & \\
\hline \multirow[t]{3}{*}{ Coeliac children } & Positive & 41 & 89.1 & 3 & 6.5 & 0.0001 \\
\hline & Negative & 5 & 10.9 & 43 & 93.5 & \\
\hline & Total & 46 & & 46 & & \\
\hline \multirow[t]{3}{*}{ Coeliac adults } & Positive & 22 & 68.7 & 0 & 0 & 0.00001 \\
\hline & Negative & 10 & 31.3 & 32 & 100 & \\
\hline & Total & 32 & 100 & 32 & 100 & \\
\hline
\end{tabular}


Table III. Comparison between EMA tests in coeliac patients before and after GFD according to age group

\begin{tabular}{|c|c|c|c|c|c|c|}
\hline & \multirow[t]{2}{*}{ EMA } & \multicolumn{2}{|c|}{ Before GFD } & \multicolumn{2}{|c|}{ After GFD } & \multirow[t]{2}{*}{ Value of $p$} \\
\hline & & $N$ & $\%$ & $N$ & $\%$ & \\
\hline \multirow[t]{3}{*}{ Coeliac children } & Positive & 43 & 93.5 & 2 & 4.3 & 0.0001 \\
\hline & Negative & 3 & 6.5 & 44 & 95.7 & \\
\hline & Total & 46 & 100 & 46 & 100 & \\
\hline \multirow[t]{3}{*}{ Coeliac adults } & Positive & 32 & 100 & 0 & 0 & 0.00001 \\
\hline & Negative & 0 & 0 & 32 & 100 & \\
\hline & Total & 32 & 100 & 32 & 100 & \\
\hline
\end{tabular}

Table IV. Comparison between tTG tests in coeliac patients before and after GFD according to age group

\begin{tabular}{|c|c|c|c|c|c|c|}
\hline & \multirow[t]{2}{*}{ tTG Ab } & \multicolumn{2}{|c|}{ Before GFD } & \multicolumn{2}{|c|}{ After GFD } & \multirow[t]{2}{*}{ Value of $p$} \\
\hline & & $N$ & $\%$ & $N$ & $\%$ & \\
\hline \multirow[t]{3}{*}{ Coeliac children } & Positive & 43 & 93.5 & 4 & 8.7 & 0.0001 \\
\hline & Negative & 3 & 6.5 & 42 & 91.3 & \\
\hline & Total & 46 & 100 & 46 & 100 & \\
\hline \multirow[t]{3}{*}{ Coeliac adults } & Positive & 32 & 100 & 0 & 0 & 0.00001 \\
\hline & Negative & 0 & 0 & 32 & 100 & \\
\hline & Total & 32 & 100 & 32 & 100 & \\
\hline
\end{tabular}

a GFD for at least 12 months can result in increased body weight, body mass index, fat mass, bone mass, triceps skin fold thickness, and nutritional and biochemical status including iron absorption [8]. However, studies have shown that whilst small bowel histology improves following a GFD, the small bowel does not generally normalize within 12 months [4, 18]. Histopathological examination allows direct visualization of the degree of mucosal damage, allowing appropriately tailored follow-up strategies to be formed using not only gastrointestinal symptoms but also recognizing patients with refractory CD $[4,18,19]$.

Histological recovery profiles of 78 patients with CD in our study revealed that only $63.1 \%$ of the children patients and $81.3 \%$ of adult patients reached complete histological remission within 1 year \pm 1 month. Meanwhile, within this time, $15.2 \%$ among the children group and $9.4 \%$ among the adult group were in remission (Marsh I). Recovery numbers in cases with subtotal or total villous atrophy (Marsh IIIb and IIIc) were lower than those in subjects with partial villous atrophy (Marsh IIla): $10.9 \%$ and 3.1\% among children and adults respectively. After 1 year \pm 1 month of follow-up, $15.2 \%$ of children patients and $3.1 \%$ of adult patients with CD still had at least partial villous atrophy; these are considered to have clinically refractory CD (Table I).

Histological non-response to GFD manifests as persistent features of enteropathy on mucosal biopsy [20]. This should provide the clue to search for other causes of $C D$. Other causes include pancreatic insufficiency, secondary lactose deficiency, bacte- rial and parasitic overgrowth, coexisting inflammatory bowel disease, collagenous colitis and lymphocytic colitis [21]. Hence, it is important to determine the presence of persistent villous atrophy and then refractory CD is diagnosed [20-22].

The response to gluten withdrawal in patients is variable, and notably, the clinical, histological, and serological responses often do not occur in parallel. Clinically, a marked symptomatic improvement may occur within several days, whereas mucosal improvement may take up to 2 years [23]. Histological response is characterized by a significant increase in villous size (reduction in villous atrophy), reduction in crypt hyperplasia and finally a reduction in the IEL count. Many responding patients may have continued mild elevation of the IEL count (Marsh I) (10 patients in this study), despite normalization of villous architecture and normal crypt size. This indicated that the expression of gluten hypersensitivity as enteropathy is measurable only if a count of IELs was performed, even if it may be minimal. This was consistent with other studies [23, 24]. Furthermore, the recovery among the adult group in our study seemed to progress faster and more completely than among children; this may be because the group of adults diagnosed with CD in our cohort was small. Until the early 2000s, endoscopies in Iraqi adults were performed only in advanced GIT diseases, which is why the majority of adult cases of CD in Iraq have been misdiagnosed. On the other hand, in Iraq, clinicians still depend on their patients' own follow-up due to severe lack of dieticians in our hospitals. However, self-repor- 
ting of compliance with a GFD that is followed in other countries at clinics is open to erroneous reporting by the patient [25]. Self-reported measuring of compliance is achievable and should be used in routine clinical practice far more frequently than objective measures.

As $C D$ has revealed itself to be more common in Iraq than previously thought [12-15], and the clinical picture of the untreated condition is protean, the use of CD antibody tests has increased significantly [26]. Coeliac antibodies such as AGA, EMA and t-TG antibodies are widely used now in clinical practice. Although still believed to reliably suggest adherence to the diet and indirectly to predict resolution of mucosal histological abnormalities, they do not indicate complete villous recovery and cannot substitute for follow-up biopsy. However, the persistence of serum antibodies is a reliable indicator of both poor diet compliance and mucosal impairment [26, 27].

There were high numbers of negative antibodies in this work, among 46 children and 32 adult coeliac subjects after commencing GFD, but still 3-4 child patients showed positive serology either in one test or more than one test. The positive results indicated either that the patient was not on a strict GFD, especially in children, or there was no response to the GFD. This study has demonstrated that all three markers AGA, EMA, and anti-tTG antibody measurements in the Iraqi $C D$ population are useful in clinical practice. We have confirmed that strict glutenfree dietary adherence leads to normalization of coeliac antibodies. This was consistent with many studies in other countries $[5,27,28]$ but our study has also confirmed that in the setting of CD followup, there are no advantages of anti-tTG antibody over EMA among Iraqi CD patients as an indicator of response to GFD. This finding was not consistent with other reports [24, 29-32], and may be related to differences in ethnicity.

In conclusion, this study has shown that repeating the duodenal biopsy 1 year \pm 1 month after diagnosis and starting a GFD supports the routine measurement of using histological findings as a gold standard test to confirm recovery of CD patients along with using known coeliac serology antibodies. Our data also indicated that serological assay for coeliac antibodies could be used as a first-level investigation before noninvasive testing in the diagnostic panel for CD to avoid unnecessary biopsies. Moreover, data have also confirmed that in the setting of serological CD follow-up, there are no advantages of anti-tTG antibody over EMA among Iraqi CD patients as an indicator of response to GFD.

\section{Acknowledgments}

The authors would like to thank staff of Pathology and Immunology units at Teaching Laborato- ries of Medical City in Baghdad for technical support for this work.

\section{References}

1. Anderson RP. Coeliac disease: current approach and future prospects. Intern Med J 2008; 38: 790-9.

2. Cummins AG, Alexander BG, Chung A, et al. Morphometric evaluation of duodenal biopsies in celiac disease. Am J Gastroenterol 2011; 106: 145-50.

3. Pietzak MM. Follow-up of patients with celiac disease: achieving compliance with treatment. Gastroenterology 2005; 128 (4 Suppl 1): S135-41.

4. Bardella MT, Velio P, Cesana BM, et al. Coeliac disease: a histological follow-up study. Histopathology 2007; 50: 465-71.

5. Hopper AD, Hadjivassiliou M, Hurlstone DP, et al What is the role of serologic testing in celiac disease? A prospective, biopsy-confirmed study with economic analysis. Clin Gastroenterol Hepatol 2008; 6: 314-20.

6. Lee SK, Lo W, Memeo L, Rotterdam H, Green PH. Duodenal histology in patients with celiac disease after treatment with a gluten-free diet. Gastrointest Endosc 2003; 57: 187-91.

7. British Society of Gastroenterology. Guidelines for the Management of Patients with Coeliac Disease. http://www. bsg.org.uk.

8. AGA Institute. AGA Institute Medical Position Statement on the Diagnosis and Management of Celiac Disease. Gastroenterology 2006; 131: 1977-80.

9. Shmerling DH, Franckx J. Childhood celiac disease: a longterm analysis of relapses in 91 patients. J Pediatr Gastroenterol Nutr 1986; 5: 565-9.

10. Congdon P, Mason MK, Smith S, Crollick A, Steel A, Littlewood J. Small-bowel mucosa in asymptomatic children with celiac disease. Mucosal changes with gluten-free diets. Am J Dis Child 1981; 135: 118-21.

11. Grefte JM, Bouman JG, Grond J, Jansen W, Kleibeuker JH. Slow and incomplete histological and functional recovery in adult gluten sensitive enteropathy. J Clin Pathol 1988; 41: 886-91.

12. Osman MT, Al-Nasiry S. Clinico-pathological evaluation of coeliac disease in Iraq. J Fac Med Baghdad 2004; 46: 10-4.

13. Al-Bayatti SM. Etiology of chronic diarrhea in Iraq. Saudi Med J 2002; 23: 675-9.

14. Mansour AA, Najeeb AA. Coeliac disease in Iraqi type 1 diabetic patients. Arab J Gastroenterol 2011; 12: 103-5.

15. Osman MT. Broad look to coeliac disease in Iraq. A PhD thesis in Pathology. Baghdad: University of Baghdad; 2004.

16. Marsh MN. Gluten, major histocompatibility complex, and the small intestine. A molecular and immunobiologic approach to the spectrum of gluten sensitivity ('celiac sprue'). Gastroenterology 1992; 102: 330-54.

17. Oberhuber G, Granditsch G, Vogelsang H. The histopathology of coeliac disease: time for a standardized report scheme for pathologists. Eur J Gastroenterol Hepatol 1999; 11: 1185-94.

18. Tursi A, Brandimarte G, Giorgetti GM, et al. Endoscopic and histological findings in the duodenum of adults with celiac disease before and after changing to a gluten-free diet: a 2-year prospective study. Endoscopy 2006; 38: 702-7.

19. Ludvigsson JF, Brandt L, Montgomery SM. Symptoms and signs in individuals with serology positive for celiac disease but normal mucosa. BMC Gastroenterol 2009; 9: 57.

20. Wahab PJ, Meijer JW, Mulder CJ. Histologic follow-up of people with celiac disease on a gluten-free diet: slow and incomplete recovery. Am J Clin Pathol 2002; 118: 459-63. 
21. Ryan BM, Kelleher D. Refractory celiac disease. Gastroenterology 2000; 119: 243-51.

22. Bai D, Brar P, Holleran S, Ramakrishnan R, Green PH. Effect of gender on the manifestations of celiac disease: evidence for greater malabsorption in men. Scand J Gastroenterol 2005; 40: 183-7.

23. Brar P, Lee AR, Lewis SK, Bhagat G, Green PH. Celiac disease in African-Americans. Dig Dis Sci 2006; 10: 1007.

24. Lidums I, Teo E, Field J, Cummins AG. Capsule endoscopy: a valuable tool in the follow-up of people with celiac disease on a gluten-free diet. Clin Transl Gastroenterol 2011; 2: e4.

25. Green PH, Rostami K, Marsh MN. Diagnosis of coeliac disease. Best Pract Res Clin Gastroenterol 2005; 19: 389-400

26. Fasano A, Berti I, Gerarduzzi T, et al. Prevalence of celiac disease in at-risk and not-at-risk groups in the United States: a large multicenter study. Arch Intern Med 2003; 163: 286-92.

27. Jones R. Coeliac disease in primary care. BMJ 2007; 334 704-5.

28. Uhlig HH, Lichtenfeld J, Osman AA, Richter T, Mothes T. Evidence for existence of coeliac disease autoantigens apart from tissue transglutaminase. Eur J Gastroenterol Hepatol 2000; 12: 1017-20.

29. Dickey W, McMillan SA, Hughes DF. Sensitivity of serum tissue transglutaminase antibodies for endomysial antibody positive and negative coeliac disease. Scand J Gastroenterol 2001; 36: 511-4.

30. Ziółkowski BA, Pacholec A, Muszyński JT. Alarm symptoms, risk factors for digestive tract cancer and readiness to participate in an endoscopic screening program. Prz Gastroenterol 2013; 8: 108-14.

31. Iwańczak F, Iwańczak B. New guidelines for diagnosis and treatment of coeliac disease in children and adolescents. Prz Gastroenterol 2012; 7: 185-91.

32. Zwolińska-Wcisło M, Tomaszewska R, Rozpondek P, Przybylska M, Mach T. Mucosal lesions of the gastric mucosa in adult patients with coeliac disease. Prz Gastroenterol 2012; 7: 291-8. 